\title{
Discolouration of polyamide microcrystalline denture base plates after exposure to filter cigarette smoke
}

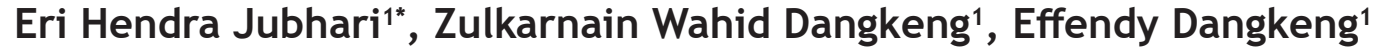 \\ 'Department of Prosthodontics, Faculty of Dentistry Hasanuddin University, Indonesia
}

\begin{abstract}
Introduction: Denture users with smoking habit often complain about colour changes in their dentures, especially on the base part. Polyamide microcrystalline is a thermoplastic denture base material and does not undergo many colour changes. The purpose of this study was to analyse the effect of filter cigarettes smoke exposure on the colour of polyamide microcrystalline materials. Methods: This study used posttest only control group design - plate-shaped sample with a size of $2 \times 2 \times 0.5 \mathrm{~cm} 3$. Nine samples as controls were immersed without exposure to the cigarette smoke, and 9 samples were immersed in artificial saliva with exposure to the filter cigarette smoke by six cycles, where one cycle was in the form of smoke exposure from one cigarette at 30-minute intervals. Cigarette exposure lasts for 21 days using a smoking simulation tool. Every seven days of exposure, colours were evaluated using a DSLR camera. The photos were then analysed with Adobe ${ }^{\mathrm{TM}}$ Photoshop in the CIELab colour space. The results were analysed afterwards by a one-way ANOVA variant test, and advance difference tests were analysed using a Post-Hoc test. Results: There was a significant colour change after exposure $(p<0.05)$, but the control group did not experience discolouration. The highest rate of colour change occurred in the second week, while in the third week the colour changes still occurred but tend to be stable. Conclusion: Exposure to the filter cigarette smoke changes the colour of polyamide microcrystalline denture base.
\end{abstract}

Keywords: Polyamide microcrystalline, filter cigarette smoke, discolouration, denture base

p-ISSN 1979-0201; e-ISSN 2549-6212; Available from: http://jurnal.unpad.ac.id/pjd/article/view/15531

DOI: $10.24198 /$ pid.vol31no2.15531

Submission: Feb 02, 2018; Reviewed: Nov 02, 2018; Resubmit for review: Mar 19, 2019; Accepted: Jun 27, 2019; Published online: Jul 31, 2019

\section{INTRODUCTION}

A removable denture is one type of dental care device with considerable interest. ${ }^{1,2}$ Materials for the manufacture of denture bases are generally made of polymethyl methacrylate (PMMA) or acrylic; a variety of alternative materials have been studied, one of which is a thermoplastic material. Thermoplastic material has more flexible physical properties that make it more comfortable to use. The use of thermoplastic materials enhances aesthetics because they do not require any clasp. Polyamide microcrystalline is a thermoplastic denture base material.

One of the physical properties of polyamide microcrystalline is controllable flexibility because 
the shrinkage is less than $1 \%$. Also, polyamide microcrystalline has a high density so that the liquid cannot penetrate it, and there is no yellow or brown colour that often appears in other materials.

Many denture users do not leave smoking habits, even though it is not suitable for maintaining the quality and aesthetics of dentures. When denture users smoke, dentures will be exposed to several substances that can affect their dentures, including carbon monoxide, formaldehyde, radioactive polonium, ammonia, nickel, arsenic, nicotine, tar, and heavy metals such as cadmium and lead. ${ }^{5}$

Some previous research states that cigarette smoke can affect the colour and surface roughness of the composites, artificially acrylic teeth on various other dentures. The factor of surface roughness level of suitable denture base is very significant to be studied because it is a place for accumulation of microorganisms, thus increasing the level of stain in dentures..$^{6-8}$

However, the previous study of the influence of cigarette smoke on denture bases was conducted towards an acrylic base. ${ }^{6-8}$ Therefore, this research was aimed to analyse the effect of filter cigarettes smoke exposure on the colour of polyamide microcrystalline materials.

\section{METHODS}

This research was experimental laboratory with posttest only control group design, carried out in the Integrated Laboratory of the Faculty of Dentistry Hasanuddin University. The samples were $2 \times 2 \times 0.5 \mathrm{~cm}^{3}$ plates made from polyamide microcrystalline (ThermoSens $\AA$ ). A total of 9 control group samples, without exposure to cigarette smoke, were immersed in artificial saliva. The other nine samples were immersed in artificial saliva and then placed in a simulation jar, and 6 filter cycles of cigarette smoke (Sampoerna ${ }^{\circledR}$ A Mild) exposure was performed. One exposure cycle was exposure to smoke from one cigarette at 30-minutes interval. Once every seven days, the study sample was photographed with a DSLR camera, and the colour change was measured using Adobe ${ }^{\circledR}$ Photoshop CS3, then analysed using the SPSS version 16 program.
The change in colour of the sample was measured by comparing acrylic artificial teeth that were not exposed to cigarette smoke exposure with artificial teeth exposed to filter cigarette smoke. Adobe ${ }^{\circledR}$ Photoshop CS3 version 10.0 was used to get $L^{*} a$ * $b$ colour space data $\left(L^{*} a * b\right.$ is a method of the Adobe ${ }^{\circledR}$ Photoshop CS3 version 10.0 application to analyse colours on an object) from sample photos. Then the data was assessed using the CIELab colour space.

The data were first tested for normality using the Kolmogorov-Smirnov normality test. The effect of cigarette smoke on colour changes was tested with ANOVA, then a post hoc LSD test was further performed to determine the most significant sample group.

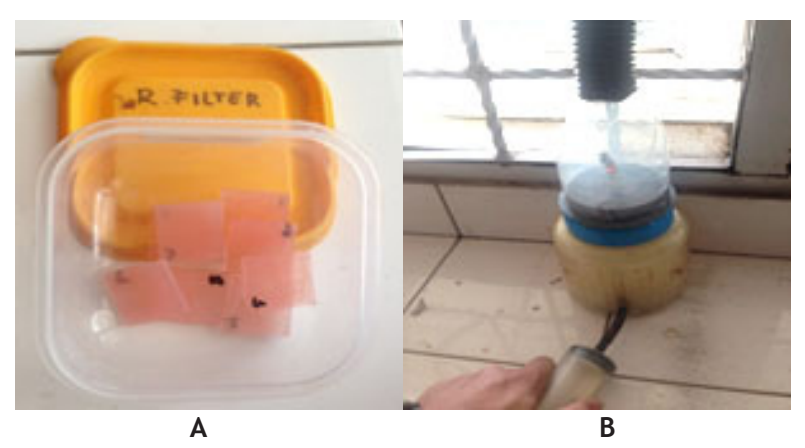

Figure 1.A. Samples from microcrystalline polyamide materials; B. Simulation device for smoking and exhaling cigarette smoke (Personal documentation)

\section{RESULTS}

The Kolmogorov-Smirnov normality test results showed a significant value in the first week, which was 0.190 , in the second week was 0.062 , and the third week was 0.200 . Significant values on all test results of this data were above 0.05 , which means that all data were normally distributed.

Colour changes in the polyamide microcrystalline base material due to exposure to filter cigarettes were shown in Table 1. Testing with ANOVA gets a value of significant changes between the control group and filter cigarette groups.

Table 2 shows the average colour change that occurred in denture base samples from microcrystalline polyamide material due to exposure to filter cigarette smoke. The colour change in the first week looks quite significant at 5.9. Numbers were based on the results of 


\begin{tabular}{cccc}
\hline \multicolumn{5}{c}{ Table 1. Data normality test } \\
\hline Week of exposure & Statistics & df & Sig. \\
\hline First week & .229 & 9 & .190 \\
Second week & .268 & 9 & .062 \\
Third week & .156 & 9 & $.200^{*}$ \\
\hline
\end{tabular}

Kolmogorov-Smirnov test, sig > 0.05; normally distributed

Table 2. Discolouration in exposure to filter cigarette

\begin{tabular}{ccc}
\multicolumn{3}{c}{ smoke } \\
\hline \multirow{2}{*}{ Week } & \multicolumn{2}{c}{ Mean of change } \\
\cline { 2 - 3 } & Control & Filter cigarette \\
\hline 1 & 0 & 5.9 \\
2 & 0 & 16.1 \\
3 & 0 & 17.1 \\
\hline
\end{tabular}

the analysis using CIELab. In the second week, the colour change were increasing very high, as much as 10.2 , the number of values in the first week, while in the third week the colour change also increased by 1.0 from the value in the second week to 17.1. Colour changes were not seen in the control group.

Table 3 shows the comparative data on the value of colour changes that occur due to exposure to cigarette smoke filters every week. The mean difference shows the value of the difference that was increasing from week to week, and it appeared that the significance value was smaller than 0.05 , indicated a significant change.

Table 3. Colour change analysis with post hoc follow-up test

\begin{tabular}{lccccc}
\hline Dependent variable & $(\mathrm{I})$ week & $(\mathrm{J})$ week & Mean difference (I-J) & Std. Error & Sig. \\
\hline \multirow{3}{*}{ Filter cigarette } & First week & Second week & $-10.4578^{*}$ & .1097 & .000 \\
& & Third week & $-11.0578^{*}$ & .1097 & .000 \\
& Second week & First week & $10.4578^{*}$ & .1097 & .000 \\
& & Third week & $-.6000^{*}$ & .1097 & .000 \\
& \multirow{2}{*}{ Third week } & First week & $11.0578^{*}$ & .1097 & .000 \\
& & Second week & $.6000^{*}$ & .1097 & .000 \\
\hline
\end{tabular}

\section{DISCUSSION}

The smoking habit is often done by denture users, which declines the quality of the denture. ${ }^{1}$ In this study, it appears that the toxic substance from cigarette smoke during smoking was able to affect dentures (Table 2). This result was consistent with research conducted by Patil et $\mathrm{al}^{2}$, Wasilewskim et $\mathrm{al}^{3}$, and Casemiro et $\mathrm{al}^{4}$, who stated that cigarette smoke could affect the colour and some mechanical properties of denture bases.

Although polymethyl methacrylate is a material commonly used for the manufacture of denture bases, there are various alternative materials available, for example, thermoplastic materials. Because of its more flexible nature, bases made from thermoplastic materials are more comfortable to use. Also, thermoplastic materials are more aesthetic because they do not use metal grips. Polyamide microcrystalline is a thermoplastic material that can be used for denture bases. ${ }^{9}$ The flexibility of this material can be controlled at the time of manufacture, and its shrinkage is relatively small. ${ }^{5}$ This thermoplastic material has a good biocompatibility level, high strength, and very low shrinkage. ${ }^{10}$ Besides the density level is high so the liquid cannot penetrate this material, thereby preventing yellow or brown discolouration. ${ }^{6,11}$

Table 2 shows the colour changes that occur permanently on the plates, and the result was consistent with the result of the study conducted by Mahros et $\mathrm{al}^{7}$, suggested that exposure of cigarette smoke to acrylic resin plates increased the roughness of the surface, which caused by the substance of cigarette smoke that attached to the plat surface. Cigarette smoke contains carbon monoxide, carbon dioxide, nicotine, ammonia, nickel, arsenic, tar and heavy metals such as lead and cadmium..$^{8,12}$ Increasing surface roughness of acrylic plates caused by the attachment of these substances cannot be lost simply by cleaning it with water.

Based on the research of Mathias et $\mathrm{al}^{13}$, cigarettes contain tar, which is an aromatic hydrocarbon that has the potential to damage polymeric materials. An ingredient obtained from the polymerisation cannot be degraded by the oral cavity fluid but can only be dissolved with some aromatic hydrocarbon liquids. ${ }^{13}$ Cigarette smoke in the oral cavity will also mix with saliva, thus becoming a liquid that has acidity, which will 
damage the surface integrity of acrylic dentures. ${ }^{14}$

Cigarette smoke contains air, water, carbon monoxide, carbon dioxide and tar. Tar, which is the main content of tobacco, can cause stains. About $0.2 \%$ tar is the brown pigment from cigarette smoke. As soon as the cigarette is burned, in the smoke, other substances from cigarette smoke are formed immediately due to heating. ${ }^{2,15}$ Also, some components of food, such as sugar and chocolate can also cause discolouration on the base because of its dark colour and its ability to adhere to the surface of the base acrylic due to heat from cigarettes.

There was a change in the colour of the base plate in this study (Table 2). The base material made from polymerisation can dissolve in aromatic hydrocarbon liquids. Table 3 shows the colour changes that occur from the first week to the third week. Exposure to cigarette smoke over some time can change the colour of the denture base made from polyamide microcrystalline (Table 2 ). Colour changes caused by filter cigarette smoke occur due to the presence of carbon, tar, and nicotine, which can change colour and the presence of food retentions attached to the surface of the base. Also, the content of cigarette smoke can dissolve polymers that may change the surface integrity of the base material to become rougher.

\section{CONCLUSION}

Exposure to the filter cigarette smoke changes the colour of polyamide microcrystalline denture base.

\section{REFERENCES}

1. dos Santos Bertold CE, de Azevedo Miranda D, Souza-Júnior EJ, Aguiar FHB, Lima DANL, Ferreira RL, et al. Surface hardness and colour change of dental enamel exposed to cigarette smoke. Int J Dent Clin 2011; 3(4): 1-4

2. Patil SS, Dhakshaini MR, Gujjari AK. Effect of cigarette smoke on acrylic resin teeth. J Clin Diagn Res 2013; 7(9): 2056-9. DOI: $10.7860 /$ JCDR/2013/6086.3404

3. Wasilewskim MDSA, Takahashi MK, Kirsten GA, De Souza EM. Effect of cigarette smoke and whiskey on the colour stability of dental composites. Am J Dent. 2010; 23(1): 4-8

4. Casemiro LA, Gomes Martins CH, Pires-de-
Souza Fde C, Panzeri H. Antimicrobial and mechanical properties of acrylic resins with incorporated silver-zinc zeolite- Part I. Gerodontol 2008; 25(3): 187-94. DOI: 10.1111/j.1741-2358.2007.00198.x

5. Hamad T, Fatalla AA, Abdulsahib AJ. The effect of different investment materials on dimensional accuracy and surface roughness of thermosens maxillary complete denture. J Bagh Coll Dent. 2015; 27(3): 1-7. DOI: 10.12816/0015026

6. Vertex Dental. Vertex ${ }^{\mathrm{TM}}$ ThermoSens: Natural feel and esthetic look [product brochure]. Singapore: Vertex dental; 2014.

7. Mahross HZ, Mohamed MD, Hassan AM, Baroudi K. Effect of cigarette smoke on surface roughness of different denture base materials. J Clin Diagn Res. 2015; 9(9): ZC39-42. DOI: 10.7860/JCDR/2015/14580.6488

8. Ayaz EA, Altintas SH, Turgut S. Effects of cigarette smoke and denture cleaners on the surface roughness and colour stability of different denture teeth. J Prosthet Dent. 2014; 112(2): 241-8. DOI: 10.1016/j. prosdent.2014.01.027

9. Hamouda IM, Faramay AMG. Aged flexural properties of vertex thermosens versus conventional denture base material for one years water storage. Austin J Dent. 2018; 5(2): 1101.

10. Vertex Dental. Premium denture solutions: Products and academy [product brochure]. Singapore: Vertex Dental. 2014.

11. Vertex Dental [homepage on internet]. Singapore: Vertex Dental. 2014. Vertex ThermoSens. [cited 2017 Dec]; [about 3 screens]. Available from: https: / / www.vertexdental.com/en/products/26-en/26/218vertex-thermosens

12. Kuhar M, Funduk N. Effect of polishing techniques on the surface roughness of acrylic denture base resins. J Prosthet Dent. 2005; 93(1): 76-85. DOI: 10.1016/j. prosdent.2004.10.002

13. Mathias P, Silva LD, Saraiva Lde O, Costa L, Sampaio MD, de Araujo RP, et al. Effect of surface sealant and repolishing procedures on the colour of composite resin exposed to cigarette smoke. Gen Dent. 2010; 58(4): 3315. 
14. Tandon R, Gupta S, Agarwal SK. Denture base material: from the past to the future. Ind $\mathrm{J}$ Dent Sci. 2010; 2(2): 33-9. DOI: 10.0910/ dentsci.2010.02.33

15. Alandia-Roman CC, Cruvinel DR, Sousa
$A B$, Pires-de-Souza FC, Panzeri H. Effect of cigarette smoke on colour stability and surface roughness of dental composites. J Dent. 2013; 41 Suppl 3: e73-9. DOI: 10.1016/j. jdent.2012.12.004 